\title{
Relevance Of Temperament Traits In Sexual Fluidity In A Sample Of Spanish Young University Students
}

\author{
Sbrana, Serena \& de Miguel, Adelia
}

\begin{abstract}
Assessing the relevance of temperament traits to predict sexual fluidity, taking into account gender and sexual orientation, was the main goal of this paper. Participants (435 Spanish young-adults students, 310 females and 125 males) completed an online questionnaire, which included measures of sexual fluidity, the short version of the Big Five Inventory, two factors of Sensation Seeking Scale, and State-Trait Anxiety Inventory. Analyses showed gender differences in sexual fluidity, anxiety and sensation seeking. Sexually fluid individuals also reported higher scores than no-sexually fluid individuals in these factors. Bisexual orientation, anxiety-trait and sensation seeking were good predictors of female sexual fluidity. Anxiety state was relevant to male sexual fluidity. We concluded that sexual fluidity can be related to emotional and biological personality traits, but it is not clear if the origin of this relationship is only biologically caused or depends on experience moderator effects. Again, the controversy nature-nurture is needed to be considered when assessing sexual fluidity across life-span.
\end{abstract}

Key words: gender, sexual fluidity, sexual orientation, personality

\section{Sexual fluidity}

\section{INTRODUCTION}

The Institute of Medicine defines sexual orientation as a multi-dimensional construct composed by attractions, sexual behaviour and sexual orientation identity (Sanders, Feit, \& Alper, 2013). Many people experience dissonances among their individual sexuality components through their sexual development. The research on sexual minority women (Diamond, 2008) introduced the possible change of sexual orientation identity in women like a capacity for situation-dependent flexibility in sexual responsiveness, which allows individuals to experience changes in desire and behavior to same-sex or other-sex across both short-term and long-term periods. Sexual fluidity, as a capacity for change in erotic responsiveness to both sexes, depends on context and life events.

In general, a growing body of research on sexual fluidity reveals that women are more sexually fluids than men (Diamond, 2008; Diamond, 2016; Kinnish, Strassberg, Turner, 2005). The main objective contemporary theories is to explain sexual fluidity. The first one is developed from evolutionary psychology, and has proposed the alloparenting hypothesis for sexual fluidity exclusively in women. Second theory, is based on Kelly's Personal Construct Theory and tries to understand and explain the sexual identity development in both women and men. 
Sbrana, Serena, \& De Miguel, A. (2020) Relevance Of Temperament Traits In Sexual Fluidity In A Sample Of Spanish Young University Students. Advances in Social Sciences Research Journal, 7(5) 369-381.

The alloparenting hypothesis states "... that sexual fluidity in women is a contingent adaptation that increased ancestral women's ability to form pair bonds with female alloparents who helped them rear children to reproductive age" (Kuhle \& Radtke, 2013, p. 304). Sexual fluidity is considered as a conditional reproductive strategy developed by ancestral women to assure resources and care for their offspring. The possibility of developing affective and sexual bonds with both a person of the same sex and of the opposite sex would be an innate characteristic in many heterosexual women. Sexual fluidity would be an adaptive product for women because although it does not facilitate procreation, it does guarantee the survival of the offspring. If should be kept in mind that, from and evolutionary point of view, the primacy is procreation. The arguments used to justify this adaptation are based on comparative psychology and female arousal and genital responses. The alloparenting hypothesis does not justify homosexual behavior but an adaptive behavior in evolutionary history of women.

According to the Theory of Personal Construction, sexual identity can be dependent on constructive alternativism which does not reveal itself to people directly and it is subject to as many alternative interpretations as people themselves invent (Kelly, 1995). Horley and Clarke (2016) added two new corollaries to PCT to explain sexual identity construction. The Source corollary refers to individual's constructs as a unique creation or an outcome of environmental experience, particularly "languagecentered social experiences" (p. 911). The Relational corollary refers to the quality of transactions with other individuals (physical attributes, social inequalities, and social power). Sexual experiences have an important impact on the self-awareness of a person. Sexual desire would depend on a large number of factors, which include individual's construction system, especially the sexual subsystem. All individuals may choose their construction but they cannot know where their entire system may lead them. People can attempt to predict the outcome of real events by adopting a set of flexible constructs, in a modifiable network. In this respect, changing sexual identity or orientation is not easy, but it is a long-term project involving self-reflections and social support. According to this proposal, "many of us, both young and old, are constantly trying to make sense of ourselves and other around us in term than can be construed, broadly speaking, to be sexual" (Horly and Clarke, 2016, p. 914). The messages the people are sending to child, young people or adults can be internalized and increase sexual identity throughout that person's life. Parents and siblings' behavior and words provide feedback about emerging sexual-self. For example, terms like "queer" or "weirdo" used by older brothers could become easily internalized by sensitive younger brother (Iuduci \& Verdecchia, 2015). When adult, the individual is also affected by relationships when is constructing his/her sexual-self, as they could became sexually fluid if him/her social relations takes place either in a gay or a straight culture (Halperin, 2010). If mistakes in constructions are made, getting a sexually fluid identity could result in a disaster with anxiety experiences, and maybe develop into a situation without turn back/solution.

Empirical support is needed for both theoretical propositions. Horly and Clarke (2016) concluded PCT provides a coherent basis of stability and change in sexual identity and desires, but there are still no studies that support this idea. Kuhle and Radtke (2013) also concluded that alloparenting hypothesis supplies a plausible account for sexual fluidity in women, but evolutionary psychology has not yet paid enough attention to the issue of sexual minorities. 


\section{Personality, sexual orientation and gender}

There is a large body of research regarding mental health among sexual minorities compared with heterosexual people (Cochran \& Mays, 2000; Needham, 2012; Strutz, Herring \& Halpern, 2015), and a large number of studies are investigating how personality is connected with gender and sexual orientation. However, there is no information about the mental health and dissonances in sexual orientation such as sexual fluidity.

At the beginning, Five-Factor Model of personality considered temperament (neuroticism, extroversion, openness to experience, agreeableness, and conscientiousness) like basic tendencies, not affected by experiences but they do affect the characteristic adaptations (life projects, values, and so) and self-concept (Costa \& McCrae, 1996), due to their interaction with culture context and interpersonal relations. Therefore, the features will be related to both normal psychological functioning and psychological suffering, being individual differences an essential question to take into account. Studies focused on Big Five factors document that gender difference tends to be the strongest for agreeableness and neuroticism, being women higher than men on both traits (Costa, Terracciano \& McCrae, 2001; Schmitt, Realo, Voracek \& Allik, 2008). Other studies suggest that high neuroticism, low extraversion and low conscientiousness are related to a greater prevalence of internalizing problems as depression, stress and anxiety (Carver \& Connor-Smith, 2010; Jokela \& Keltikangas-Jarvinen, 2011; Lockenhoff, Ironson, O'Cleirigh, \& Costa, 2009), and the rules of neuroticism and conscientiousness can predict the occurrence of depressive symptoms (Hakulinen, Elivainino, Pilkki-Raback,, Virtanen, Kivimaki \& Jokela, M., 2015).

Considering sexual orientation, gay men would appear to be more susceptible to suffering depression. Lippa's meta-analysis (2005) found that gay men scored higher than heterosexual men on expressiveness, conscientiousness, neuroticism and openness and heterosexual women scored higher than lesbian on neuroticism. In the Bogaert, Ashton and Lee's study (2018), all nonheterosexual groups, particularly bisexual people, scored on average higher in openness to experience than did heterosexuals.

Studies have shown that sexual minorities were associated to unfavourable mental health connected to the stress associated with forming part of a stigmatized group (Hatzenbuehler 2009; Herek 2000; Mays \& Cochran 2001; Meyer 2013). Sexual fluidity can also be assessed as a kind of intra-individual sexual discordance. Little is known about health consequences of that dissonance (Talley, Aranda, Hughes, Everett \& Johnson, 2015). Chesney, Neilands, Chambers, Taylor, and Folkman (2006) asserted that an individual's coping self-efficacy is connected with stressful situation, how person's perceived ability to cope with life challenges define a relationship of coping behaviors with mental health and well-being outcomes (e.g., anxiety, stress). It is important how individuals with different sexual orientations perceive stressful events and how they can respond to them. Minority Stress Theory suggests that the exposition to social stressors (as internalized homophobia, stigma, prejudice, discrimination and violence) is related to negative mental health consequences especially among lesbian, gay and bisexual populations (Hatzenbuelher, 2009; Meyer, 1995; Meyer 2003). Researches have focused on sexual minorities groups, especially on LGB groups, but little is known about the mental statues and stress experience in sexual minority groups who describe their identity as sexually fluid. In their study, Krueger, Meyer, and Upchurch (2018) assessed the difference between perceived stress and depressive symptoms among concordant heterosexual individuals and sexual minority young adults which were composed by LGB and non- 
Sbrana, Serena, \& De Miguel, A. (2020) Relevance Of Temperament Traits In Sexual Fluidity In A Sample Of Spanish Young University Students. Advances in Social Sciences Research Journal, 7(5) 369-381.

identified LGB (mostly heterosexual and discordant heterosexual) individuals. As LGB group, nonidentified LGB group showed more depressive symptoms than concordant heterosexual individuals. Furthermore, the research showed how women expressed more variability and fluidity than men for their sexual identity labels and the analyses suggested a gender difference in stress and mental health among sexual minorities.

Sexual fluidity and bisexuality produce the same phenomenological result: sexual attractions to both, men and women (Diamond, 2016). The beliefs that bisexuals people (specifically male bisexuals) are confused about their sexual identity, and in reality are gay or lesbian, immature, emotionally incomplete, sexually promiscuous, unable be monogamous or more likely to contract HIV/AIDS are all features included in the binegativity concept (Farajaje'-Jones, 1995; Ochs, 1996; Rust, 2002; Sumpter, 1991; Yost \& Thomas, 2012). These prejudices on bisexuality can suppose a specific personality trait as sensation seeking. Elevated levels of sexual sensation seeking and sexual curiosity were found for both bisexual women and men (Stief, Rieger \& Savin-William, 2014). In the present study, sensation seeking related to sexual fluidity was investigated as a personality trait that can be involved in this construction.

The purpose of the present study was to investigate the relation between sexual fluidity with three components of personality, referred to anxiety and sensation seeking: temperament as basic traits, sensation seeking as biologically determined traits, and anxiety as trait and state (specific-reaction related to contextual situations). Gender and sexual orientation differences also have been investigated for every personality trait, and their relevance to predict sexual fluidity in the two sexes.

\section{Participants}

\section{METHOD}

The participants were 435 university students (self-identified: 310 women, 125 men), ages ranged 18-38 ( $M=21.17, S D=4.37)$ from La Laguna University, Spain. The majority of individuals were studying Health Science courses (46.7\%), and the rest of sample were studying Arts and Humanities (29.9\%), Science (29.9\%) and Law and Communication (2.6\%) courses. Sexual orientation identity was assessed with this single item, "How do you identify your sexual orientation?" Distribution regarding this item was: $54 \%(n=234)$ heterosexual women, $22.1 \%(n=96)$ heterosexual men, $2.9 \%(n=7)$ lesbian women, 3.6\% $(n=16)$ gay men, $14.5 \%(n=69)$ bisexual women and $2.9 \%(n=$ 13) bisexual men.

\section{Instruments}

\section{Sexual Fluidity}

The Sexual Fluidity Scale (SFS, Sbrana \& de Miguel, 2020, in press) is a new instrument developed using Diamond's (2003) interview, and the Sexual Fluidity Beliefs Scale (Kats-Wise \& Hyde, 2015), in order to assess sexual fluidity like an attitudinal-behaviour personality dimension. SFS consisted of 10 items rated on a 5 -point rating scale $(1=$ strongly disagree to $5=$ strongly agree). Four items were related to sexual-fluid behaviour ("I would like to have a sexual relationship with a person whose gender is not from my preferred gender"), four items related with sexual-fluid desire ("Frequently I feel sexual attraction towards people whose gender is not from my preferred gender"), and three items regarding sexual-fluid attitude ("I don't know the gender of the person to whom I will be attracted to in the future"). Cronbach's alpha was .89 . 


\section{Temperament traits}

The short version of the Big Five Inventory (Rammstedt \& John, 2007) was used to assess the personality like temperament not-influenced by environmental factors. It consisted of 10 items using a Likert scale ranging from 1 (completely disagree) to 5 (completely agree). In this study, the internal consistency for every factors were: .63 Extraversion, .12 Agreeableness, .51 Conscientiousness, .64 Neuroticism and .89 Openness. In Rammstedt's original study there was no data for alpha values and the comparison with this study was not possible to make. For each basic trait, average scores of its two items were calculated (ranged 1-5).

The Sensation Seeking Scale (SSS) (Zuckerman, 1979) was used to assess two of its four factors: Disinhibition and Boredom Susceptibility. Both of them have hormonal influences before puberty (Zuckerman, 2006). The instrument consisted of 10 items for each factor, with dichotomous response $(0=n o ; 1=$ yes $)$. Cronbach's alpha was .70 for Disinhibition and .50 for Boredom Susceptibility.

The State-Trait Anxiety Inventory (STAI, Spielberger, Gorsuch \& Lushene, 1970) is formed by 40 items: 20 items to assess State-Anxiety and 20 items to assess Trait-Anxiety. It includes a response Likert scale with 4 point, from 0 (not at all) to 3 (very much). In this study Cronbach's $\alpha$ was .89 for sub-scale State-Anxiety and .91 for sub -scale Trait-Anxiety.

\section{PROCEDURE}

This study was developed between the months of September and December in 2017. Participants were recruited from among the body of students registered in every Department of La Laguna University, Spain. The project was presented to the students who could access the URL link by the virtual area of the University (provided by either Department coordinators or student associations). Participants completed the online survey. They were informed of the nature of the research and its objectives and confidentiality of the data at the start of the survey, after this the participants gave consent and completed the survey using their own computer, smartphone or tablet. The duration of the questionnaire ranged from 20 to $40 \mathrm{~min}$. The statistical analyses were made with IBM SPSS 22.

\section{RESULTS}

Individual differences by gender and sexual orientation were analyzed by ANOVA and Student's $t$ for all target variables. Gender differences showed women scored higher than men in Sexual Fluidity (Cohen's $d=.69)$, Conscientiousness $(d=.29)$ and Neuroticism $(d=.68)$ factors, but lower in Agreeableness $(d=.23)$ and Disinhibition $(d=.30)$ factors. There were no differences between homosexual and heterosexual participants. Bisexual participants scored higher than homosexual individuals in Sexual Fluidity $(d=1.74)$, Openness to Experience $(d=.66)$ and Anxiety Trait $(d=$ $.18)$, and higher than heterosexual individuals in Sexual Fluidity $(d=1.1)$ and Openness to Experience $(d=.37)$. A single interaction effect "gender x sexual orientation" appeared for Sexual Fluidity $(F=3.26, p<.01)$ affecting homosexual and heterosexual orientations (see Figure 1).

\section{Relationships between sexual fluidity and temperament traits.}

Table 1 reports, for all target variables bivariate and partial (gender and sexual orientation controlled), correlations between Sexual Fluidity and temperament traits. Pearson's $r$ was positive and statistically significant between sexual fluidity and anxiety factors (Neuroticism $[r=.11, p<$ 
Sbrana, Serena, \& De Miguel, A. (2020) Relevance Of Temperament Traits In Sexual Fluidity In A Sample Of Spanish Young University Students. Advances in Social Sciences Research Journal, 7(5) 369-381.

$.05]$, Anxiety-trait $[r=.26, p<.01]$ and Anxiety-state $[r=.18, p<.01])$ and sensation seeking (Openness to Experience $[r=.21, p<.01]$, Disinhibition $[r=.21, p<.01]$ and Boredom Susceptibility $[r=.19, p<.01)$ ). No significant correlations were found between Sexual Fluidity and Extroversion, Agreeableness and Conscientiousness factors.

Partial correlations, controlling gender and sexual orientation, were similar to $r$, except for three BFI factors. Controlling gender allowed to appear a negative relation between Sexual Fluidity and Conscientiousness $(r=-.11, p<.05)$, and to remove the positive relation between Sexual Fluidity and Neuroticism. Controlling sexual orientation allowed seeing a negative relation between Sexual Fluidity and Agreeableness $(r=-.10, p<.05)$.

\section{Individual differences by sexual fluidity}

Using median score in SFS, the participants were assigned either to the "sexual-fluid group" if their score was higher than 23, or to the "non-sexual fluid group" if their score was equal or less than 23. Figure 1 shows subject distribution for "dummy"-Sexual Fluidity based on gender and sexual orientation. The sexual-fluid group was larger for both bisexual men and women groups in comparison with other sexual-orientation groups (see frequency number in each column). Results form 9 ANOVAs (one of each temperament traits) $2 \times 2$ (gender $\mathrm{x}$ sexual fluidity group) are showed in table 2.

Sexual fluidity main effect was significant for Openness to Experience $\left(F_{(1.434)}=14.34, p<.001, \eta^{2}=\right.$ $.03)$, Disinhibition $\left(F_{(1.434)}=9.78, p<.01, \eta^{2}=.02\right)$, Boredom Susceptibility $\left(F_{(1.434)}=8.81, p<.01, \eta^{2}\right.$ $=.02)$, Anxiety-State $\left(F_{(1.434)}=5.67, p<.01, \eta^{2}=.01\right)$, and Anxiety-State $\left(F_{(1.434)}=9.59, p<.01, \eta^{2}=.02\right)$. In all cases, sexual-fluid individuals scored higher than non-sexual-fluid individuals. There was no interaction effect between gender and sexual fluidity.

\section{Relevance of temperament traits to predict sexual fluidity}

Three multiple lineal regression analyses (one for total sample, and one for each gender) were conducted, being the criteria the direct score in sexual fluidity factor, and the predictors all of temperament traits assessed, gender and sexual orientation. Correlations among all traits are showed in table 3 and regression results in table 4.

TABLES $3 \& 4$

For the total sample, the model was significant $(p<.001)$ and accounted for $28 \%$ of the variance. Gender $(\beta=-.32, t=-7.78, p<.001)$ and sexual orientation $(\beta=-.22, t=-5.38, p<.001)$ were statistically significant, indicating that a being woman and homosexual or bisexual person predicts a higher sexual fluidity. Openness to experience $(\beta=.20, t=4.55, p<.001)$, Trait Anxiety $(\beta=.19, t$ $=4.55, p<.001)$ and Disinhibition $(\beta=23, t=5.51, p<.001)$ were positively associated with sexual fluidity.

Model for women was significant $(p<.001)$ and accounted for $24 \%$ of the variance. Traits with predictive power were the same ones that for the total sample. However, model for men, always significant $(p<.001)$, accounted a smaller percentage $(18 \%)$, and removed Trait Anxiety and included State Anxiety as a significant predictor $(\beta=.20, t=2.47, p<.01)$. Openness to Experience was more important to predict sexual fluidity in men $(\beta=.31)$ than in women $(\beta=.16)$. 


\section{DISCUSSION}

The main purpose of this study was to investigate the relation between sexual fluidity and temperament: basic tendencies like basic traits, anxiety like trait and state (contextual situations) and sensation seeking like biologically determined traits, taking into account gender and sexual orientation.

Sexual fluidity was considered earlier like a female characteristic (Diamond, 2008). Our results seem to indicate that both men and women can present themselves as sexually fluid, although it is true that the frequency of this feature was greater in people who define themselves as bisexual.

Regarding temperament as basic traits assessed by Big Five Inventory (Rammstedt \& John, 2007), there were sexual fluidity differences in Openness to Experience: sexually fluid individuals displayed higher scores than no-sexually fluid individuals. Higher levels of Openness might be considered in two ways: openness as a consequence of previous sexual experiences that led sexually fluid individuals to be more open-mind oriented, or openness as a specific sexually-fluid individual personality trait.

Sexually fluid people displayed higher levels of anxiety than no-sexually fluid participants in both state and trait measures of anxiety. This is in accord with recent researches in which more perceived stress and depressive symptoms were found in sexual minority young adults non-identified LGB than concordant heterosexual (Krueger et al., 2018). As the Minority Stress Theory suggest, the exposition to social stressor can be related to negative mental health among sexually fluid people, as it was found in lesbian, gay and bisexual population (Hatzenbuelher, 2009; Meyer, 1995; Meyer, 2003). Sexual fluidity can be reflecting a part of sexual minorities that it is currently exposed to prejudice, stigma and discrimination and for this reason, sexual fluid people could be more susceptible to negative mental health.

Regarding Sensation seeking, sexually fluid individuals reported higher scores than no-sexually fluid individuals in both subscales: Disinhibition and Boredom Susceptibility. We can suppose those constructions could be related to a greater predisposition to try different sexual experiences in sexually fluid people, according to Zuckerman theory (2006), if both factors are related with hormonal levels. There is also a gender difference in Sensation Seeking: women showed higher scores in Disinhibition and Boredom Susceptibility than men. This supports previous researches that revealed how women expressed more variability and fluidity than men for their sexual identity labels (Diamond, 2008). Disinhibition may be related to greater sense of freedom of women to express themselves, and maybe like an empowerment device. It is possible that the evolutionary theory also has some justification taking into account the studies that relate the hormonal levels with sexual practices (Gangestad, Thornhill, \& Garver-Apgar, 2005; Kanazawa, 2017).

Finally, regression results support the relevance of sensation seeking (Openness and Desinhibition), anxiety and sexual orientation (bisexuality) to predict sexual fluidity. Trait anxiety is more important for women, while state anxiety is more relevant for men. Defining the origin of these connections between sexual fluidity with personality as anxiety and sensation seeking is difficult. Personality traits and sexual fluidity could be biologically caused, so sexually fluid individuals might have different features dictated by nature. Those differences, on the other hand, may depend on 
Sbrana, Serena, \& De Miguel, A. (2020) Relevance Of Temperament Traits In Sexual Fluidity In A Sample Of Spanish Young University Students. Advances in Social Sciences Research Journal, 7(5) 369-381.

experience and social pressures, like PCT proposes in Horley and Clarke (2016) model. Naturenurture interaction must be analyzed in future researches.

\section{LIMITATION AND FUTURE DIRECTIONS}

In this study a number of limitations should be mentioned. Firstly, about the sample, university young students were recruited. Future research would include mature adults, older than 30 years old, with different features. Secondly, this is a preliminary investigation in which sexual fluidity and personality have been investigate, it is therefore necessary to conduct further researches to assess these constructions. Finally, the cross-sectional study design cannot determine the direction of the relationship of sexual fluidity with the other constructions of personality. These data are crosssectional and it is not possible to draw inferences about the causal nature of the correlation. Longitudinal study design could be supposed to investigate the real qualitative direction of sexual fluidity and possible trait of personality relations.

\section{Compliance with Ethical Standards Conflict of interest}

Authors declare that they have no conflict of interest.

\section{Human and Animal Rights and Informed Consent}

In this article, there are not any studies with animal subjects performed by any of the authors. The informed consent was obtained from all participants included in the studies.

\section{Ethical approval}

All procedures performed in studies involving human participants were in accordance with the ethical standards of the institutional and/or national research committee and with the 1964 Helsinki declaration and its later amendments or comparable ethical standards.

\section{References}

Bogaert, A. F., Ashton, M. C., \& Lee, K. (2018). Personality and Sexual Orientation: Extension to Asexuality and the HEXACO Model. Journal of sex research, 55(8), 951-961. https://doi.org/10.1080/00224499.2017.1287844

Carver, C.S., \& Connor-Smith, J. (2010). Personality and coping. Annual Review of Psychology, 61, 679-704. http://dx.doi.org/10.1146/annurev.psych.093008.100352

Chesney, M. A., Neilands, T.B., Chambers, D.B., Taylor, J.M., \& Folkman, S. (2006). A validity and reliability study of the coping self-efficacy scale. British Journal of Health Psychology, 11, 421-437.

http://dx.doi.org/10.1348/135910705X53155

Cochran, S. D., \& Mays, V. M. (2000). Relation between psychiatric syndromes and behaviorally defined sexual orientation in a sample of the US population. American Journal of Epidemiology, 151(5), 516-523.

http://dx.doi.org/10.1093/oxfordjournals.aje.a010238

Costa, P.T., \& McCrae, R.R. (1996). Toward a new generation of personality theories: theoretical contexts for fivefactor model. In J.S. Wiggins (ed.). The Five Factor Model of personality: Theoretical prospectives New York: Guilford Press.

Costa, P. T., Terracciano, A., \& McCrae, R. R. (2001). Gender differences in personality across cultures: Robust and surprising results. Journal of Personality and Social Psychology, 81, 322-331. doi: 10.1037/0022-3514.81.2.322

Diamond, L. M. (2003). Was It a Phase? Young Women's Reliquishment of Lesbian/Bisexual Identities Over a 5-years Period. Journal of Personality and Social Psychology, 2, 352-364. http://dx.doi.org/10.1037/0022-3514.84.2.352

Diamond, L. M. (2008). Sexual Fluidity. Understanding Women's Love and Desire. London: Harvard University Press. 
Diamond, L. M. (2016). Sexual Fluidity in Male e Female. Current Sexual Health Reports, 8, 249-56. http://dx.doi.org/10.1007/s11930-016-0092-z

Farajaje'-Jones, E. (1995). Fluid desire: Race, HIV/AIDS, and bisexual politics. In N. Tucker, L. Highleyman, \& R. Kaplan (Eds.). Bisexual politics: Theories, queries, and visions (pp. 119-130). New York: Harrington Park Press.

Gangestad, S. W., Thornhill, R., \& Garver-Apgar, C. E. (2005). Adaptations to ovulation: Implications for sexual and social behavior. Current Directions in Psychological Science, 14(6), 312-316. https://doi.org/10.1111\%2Fj.09637214.2005.00388.x

Hakulinen, C., Elivainino, M., Pilkki-Raback, L., Virtanen, M., Kivimaki, M., \& Jokela, M. (2015). Personality and depressive symptoms: Individual participant meta-analysis across 10 cohort studies. Depression and Anxiety, 32, 461470. http://dx.doi.org/10.1002/da.22376

Halperin, D. M. (2010). How to be gay. Cambridge: Belknap Press.

Hatzenbuehler, M. L. (2009). How does sexual minority stigma "get under the skin?"a psychological mediation framework. Psychological Bulletin, 135(5), 707-730. http://dx.doi.org/10.1037/a0016441

Herek, G.M. (2000). Sexual prejudice and gender: Do heterosexuals' attitudes toward lesbians and gay men differ? Journal of Social Issue, 56, 251-266. http://dx.doi.org/10.1111/0022-4537.00164

Horley, J. \& Clarke (2016). Costructing Sexuality: A Theory of Stability and Fluidity. Sexuality and Culture, 20,906-902. http://dx.doi.org/10.1007/s12119-016-9364-z

Iuduci, A., \& Verdecchia, M. (2015). Homophobic labeling in the process of identity construction. Sexuality and Culture, 19, 737-758. https://doi.org/10.1007/s12119-015-9287-0

Jokela, M., \& Keltikangas-Jarvinen, L. (2011). The association between low socioeconomic status and depressive symptoms depends on temperament and personality traits. Personality and Individual Differences, 51, 302-308. http://dx.doi.org/10.1016/j.paid.2010.05.004

Kanazawa, S. (2017). Possible evolutionary origins of human female sexual fluidity. Biological Reviews, 92(3), 12511274. https://doi.org/10.1111/brv.12278

Katz-Wise, S. L. \& Hyde, J., S. (2015). Sexual fluidity related attitudes and beliefs among young adults with a samegender. Archive of Sexual Behaviour, 44, 1459-1470. http://dx.doi.org/10.1007/s10508-014-0420-1

Kelly, G. A. (1955). The psychology of personal construct (Vol. 2). New York: Norton.

Kinnish, K. K., Strassberg, D. S., \& Turner, C. W. (2005). Sex differences in the flexibility of sexual orientation: A multidimensional retrospective assessment. Archives of Sexual Behavior, 34, 173-183.

http://dx.doi.org/10.1007/s10508-005-1795-9

Krueger, E. A., Meyer, I. H., \& Upchurch, D. M. (2018). Sexual orientation group differences in perceived stress and depressive symptoms among young adults in the United States. LGBT Health, 5(4), 242-249.

http://dx.doi.org/10.1089/lgbt.2017.0228

Kuhle, B. X., \& Radtke, S. (2013). Born both ways: The alloparenting hypothesis for sexual fluidity in women. Evolutionary Psychology, 11(2), 304-323. https://doi.org/10.1177\%2F147470491301100202

Lippa, R. A. (2005). Sexual orientation and personality. Archives of Sexual Behavior, 63, 119-153 https://psycnet.apa.org/doi/10.1371/journal.pone.0040256

Lockenhoff, C. E., Ironson, G. H., O'Cleirigh, C., \& Costa, P. T., Jr. (2009). Five-factor model personality traits, spirituality/religiousness, and mental health among people living with HIV. Journal of Personality, 77, 1411-1436. http://dx.doi.org/10.1111/j.1467-6494.2009.00587.x

Mays, V. M., \& Cochran, S. D. (2001). Mental health correlates of perceived discrimination among lesbian, gay, and bisexual adults in the United States. American Journal of Public Health, 91(11), 1869-1876.

http://dx.doi.org/10.2105/AJPH.91.11.1869

Meyer, I.H. (1995). Minority stress and mental health in gay men. Journal of Health and Social Behavior, 36, 38-56. http://dx.doi.org/10.2307/2137286 
Sbrana, Serena, \& De Miguel, A. (2020) Relevance Of Temperament Traits In Sexual Fluidity In A Sample Of Spanish Young University Students. Advances in Social Sciences Research Journal, 7(5) 369-381.

Meyer, I. H (2003). Prejudice, social stress, and mental health in lesbian, gay, and bisexual populations: Conceptual issues and research evidence. Psychological Bulletin, 129(5), 674-697. http://dx.doi.org/10.1037/0033-

2909.129.5.674

Meyer, I. H. (2013). Prejudice, social stress, and mental health in lesbian, gay and bisexual populations: Conceptual issues and research evidence. Psychology of Sexual Orientation and Gender Diversity, 1(S), 3-26.

http://dx.doi.org/10.1037/2329-0382.1.S.3

Needham, B. L. (2012). Sexual attraction and trajectories of mental health and substance use during the transition from adolescence to adulthood. Journal of Youth and Adolescence, 41, 179-190.http://dx.doi.org/10.1007/s10964011-9729-4

Ochs, R. (1996). Biphobia: It goes more than two ways. In B. A. Firestein (Ed.), Bisexuality: The psychology and politics of an invisible minority (pp. 217-239). Thousand Oaks, CA: Sage.

Rammstedt, B. \& John, O.P. (2007). Measuring personality in one minute or less: a 10-item short version of the Big Five Inventory in English and German. Journal of Research in Personality, 41, 203-212.

Rust, P. C. (2002). Bisexuality: The state of the union. Annual Review of Sex Research,13, 180-240.

Sanders, J. Q., Feit, M. N., \& Alper, J. (Eds.). (2013). Collecting sexual orientation and gender identity data in electronic health records: workshop summary. National Academies Press.

Sbrana, S. \& de Miguel, A. (2020). Sexual Fluidity and Attitudes to Bisexuality. puntOorg International Journal. https://doi.org/10.19245/25.05.pij.of.1.1

Schmitt, D. P., Realo, A., Voracek, M., \& Allik, J. (2008). Why can't a man be more like a woman? Sex differences in Big Five personality traits across 55 cultures. Journal of Personality and Social Psychology, 94, 168-182. 10.1037/0022$\underline{3514.94 .1 .168}$

Spielberger, C. D., Gorsuch, R. L., \& Lushene, R. E. (1970). STAI, Manual of State-Trait Anxiety Inventory (Self-Evaluation Questionnaire). Palo Alto California: Consulting Psychologist Press.

Stief, M. C., Rieger, G., \& Savin-Williams, R. C. (2014). Bisexuality is associated with elevated sexual sensation seeking, sexual curiosity, and sexual excitability. Personality and Individual Difference, 66, 193-198.

https://doi.org/10.1016/j.amepre.2014.07.038

Strutz, K. L., Herring, A. H., \& Halpern, C. T. (2015). Health disparities among young adult sexual minorities in the US. American Journal of Preventive Medicine, 48(1), 76-88. https://doi.org/10.1016/i.amepre.2014.07.038

Sumpter, S. F. (1991). Myths/realities of bisexuality. In L. Hutchins \& L. Kaahumanu (Eds.), Bi any other name: Bisexual people speak out (pp. 12-13). New York: Alyson Books.

Talley, A. E., Aranda, F., Hughes, T. L., Everett, B., \& Johnson, T. P. (2015). Longitudinal associations among discordant sexual orientation dimensions and hazardous drinking in a cohort of sexual minority women. Social Identities and Health, 56 (2), 225-245. http://dx.doi.org/10.1177/0022146515582099.

Yost, M. R., \& Thomas, G. D. (2012). Gender and binegativity: men's and women's attitudes toward male and female bisexuals. Archives of Sexual Behavior, 41, 691-702.http://dx.doi.org/10.1007/s10508-011-9767-8

Zuckerman, M. (1979). Sensation seeking: Beyond the optimal level of arousal. Hilldsdale, NJ: Erlbaum.

Zuckerman, M. (2006). Biosocial Bases of Sensation Seeking. In T. Canli (Ed.), Biology of personality and individual differences (pp. 37-59). New York, NY, US: The Guilford Press. 


\section{TABLES}

Table 1. Bivariate and partial correlations between sexual fluidity factor and temperament traits

\begin{tabular}{|c|c|c|c|c|}
\hline & \multicolumn{4}{|c|}{$r$ partial (variable controlled) } \\
\hline & Pearson & G & SO & G \& SO \\
\hline Sexual fluidity & -- & & & \\
\hline \multicolumn{5}{|l|}{ BFI } \\
\hline Extroversion & .02 & .03 & .03 & .05 \\
\hline Agreeableness & -.09 & -.06 & $-.10^{*}$ & -.08 \\
\hline Conscientiousness & -.07 & $-.11^{*}$ & -.06 & $-.10^{*}$ \\
\hline Neuroticism & $.11^{*}$ & .03 & $.12^{*}$ & .03 \\
\hline Openness to experience & $.21^{* *}$ & $.21^{* * *}$ & $.21^{* * *}$ & $.29 * * *$ \\
\hline \multicolumn{5}{|l|}{ SSS } \\
\hline Disinhibition & $.21^{* *}$ & $.27^{* * *}$ & $.21^{* * *}$ & $.27^{* * *}$ \\
\hline Boredom Susceptibility & $.19^{* *}$ & $.28^{* * *}$ & $.19^{* * *}$ & $.22^{* * *}$ \\
\hline \multicolumn{5}{|l|}{ STAI } \\
\hline Trait Anxiety & $.26^{* *}$ & $.25^{* * *}$ & $.25^{* * *}$ & $.24^{* * *}$ \\
\hline State Anxiety & $.18^{* *}$ & $.18^{* * *}$ & $.19^{* * *}$ & $.18^{* * *}$ \\
\hline \multicolumn{5}{|c|}{$\begin{aligned} \text { NOTE: } \mathrm{G}=\operatorname{gender}(0=\text { woman, } 1=\operatorname{man}) ; & \mathrm{SO}=\text { sexual orientation }(1=\text { homosexual, } 2=\text { bisexual; } 3=\text { heterosexual }) \\
& *<p .05 ;{ }^{* *} p<.01 ;{ }^{* * *} p<.001\end{aligned}$} \\
\hline
\end{tabular}

Table 2. Differences in temperament traits by gender and sexual fluidity.

\begin{tabular}{|c|c|c|c|c|c|c|c|c|c|c|c|c|c|c|}
\hline & \multicolumn{4}{|c|}{ Women } & \multicolumn{4}{|c|}{ Men } & \multicolumn{6}{|c|}{ ANOVA } \\
\hline & \multicolumn{2}{|c|}{$\begin{array}{l}\text { Sexually } \\
\text { fluid }\end{array}$} & \multicolumn{2}{|c|}{$\begin{array}{l}\text { No- } \\
\text { Sexually } \\
\text { fluid }\end{array}$} & \multicolumn{2}{|c|}{$\begin{array}{l}\text { Sexually } \\
\text { fluid }\end{array}$} & \multicolumn{2}{|c|}{$\begin{array}{l}\text { No-Sexually } \\
\text { fluid }\end{array}$} & \multicolumn{2}{|c|}{ Gender } & \multicolumn{2}{|c|}{$\begin{array}{l}\text { Sexual } \\
\text { Fluidity }\end{array}$} & \multicolumn{2}{|c|}{$\begin{array}{c}\text { Gender vs } \\
\text { Sexual } \\
\text { Fluidity }\end{array}$} \\
\hline & $M$ & $S D$ & $M$ & $S D$ & $M$ & $S D$ & $M$ & $S D$ & $\begin{array}{c}F \\
(1.434)\end{array}$ & $\eta^{2}$ & $\begin{array}{c}F \\
(1.434)\end{array}$ & $\eta^{2}$ & $\begin{array}{c}F \\
(1.434)\end{array}$ & $\eta^{2}$ \\
\hline \multicolumn{15}{|c|}{ BFI } \\
\hline Extraversion & $\begin{array}{c}2.9 \\
9 \\
\end{array}$ & $\begin{array}{c}1.0 \\
3 \\
\end{array}$ & $\begin{array}{c}2.9 \\
4 \\
\end{array}$ & $\begin{array}{c}1.0 \\
9 \\
\end{array}$ & $\begin{array}{c}3.1 \\
5 \\
\end{array}$ & 1.09 & 3.03 & .88 & 1.04 & .002 & .49 & .001 & .07 & .000 \\
\hline $\begin{array}{c}\text { Agreeablene } \\
\text { ss }\end{array}$ & $\begin{array}{c}2.9 \\
1\end{array}$ & .84 & $\begin{array}{c}3.0 \\
0\end{array}$ & .85 & $\begin{array}{c}3.0 \\
9\end{array}$ & .99 & 3.16 & .72 & 3.10 & .007 & .64 & .001 & .00 & .000 \\
\hline $\begin{array}{c}\text { Conscientio } \\
\text { usness }\end{array}$ & $\begin{array}{c}3.4 \\
0\end{array}$ & .91 & $\begin{array}{c}3.5 \\
8\end{array}$ & .97 & $\begin{array}{c}3.1 \\
9\end{array}$ & .89 & 3.23 & .88 & $7.11^{* *}$ & .016 & 1.02 & .002 & .48 & .001 \\
\hline Neuroticism & $\begin{array}{c}3.4 \\
6\end{array}$ & 1.0 & $\begin{array}{c}3.4 \\
2\end{array}$ & .99 & $\begin{array}{c}2.7 \\
6\end{array}$ & 1.12 & 2.79 & .92 & $\begin{array}{c}34.28^{* *} \\
*\end{array}$ & .074 & 7.03 & .008 & .17 & .000 \\
\hline Openness & $\begin{array}{c}4.0 \\
4 \\
\end{array}$ & .80 & $\begin{array}{c}3.7 \\
9 \\
\end{array}$ & $\begin{array}{c}1.0 \\
1 \\
\end{array}$ & $\begin{array}{c}4.2 \\
7 \\
\end{array}$ & .91 & 3.73 & .89 & .67 & .002 & $\begin{array}{c}14.34^{* *} \\
*\end{array}$ & .032 & 1.83 & .004 \\
\hline \multicolumn{15}{|c|}{ SSS } \\
\hline $\begin{array}{c}\text { Disinhibitio } \\
n\end{array}$ & $\begin{array}{c}4.7 \\
1 \\
\end{array}$ & $\begin{array}{c}2.4 \\
4 \\
\end{array}$ & $\begin{array}{c}3.6 \\
3 \\
\end{array}$ & $\begin{array}{c}2.4 \\
3 \\
\end{array}$ & $\begin{array}{c}5.3 \\
8 \\
\end{array}$ & 1.85 & 4.78 & 2.02 & $\begin{array}{c}11.50 \\
* * *\end{array}$ & .026 & $9.78^{* *}$ & .022 & .78 & .002 \\
\hline $\begin{array}{c}\text { Boredom } \\
\text { Susceptibilit } \\
\mathbf{y} \\
\end{array}$ & $\begin{array}{c}3.5 \\
2\end{array}$ & $\begin{array}{c}1.9 \\
3\end{array}$ & $\begin{array}{c}2.8 \\
2\end{array}$ & $\begin{array}{c}1.9 \\
3\end{array}$ & $\begin{array}{c}3.9 \\
1\end{array}$ & 2.35 & 3.30 & 1.64 & $3.75 *$ & .053 & $8.81^{* *}$ & .020 & .04 & .000 \\
\hline \multicolumn{15}{|c|}{ STAI } \\
\hline State & $\begin{array}{l}21 . \\
24\end{array}$ & $\begin{array}{l}11 . \\
13\end{array}$ & $\begin{array}{l}17 . \\
80\end{array}$ & $\begin{array}{l}10 . \\
18\end{array}$ & $\begin{array}{l}20 . \\
85\end{array}$ & $\begin{array}{c}10.9 \\
0\end{array}$ & $\begin{array}{c}18.3 \\
5\end{array}$ & $\begin{array}{c}10.9 \\
3\end{array}$ & .01 & .000 & $5.67^{* *}$ & .013 & .14 & .000 \\
\hline Trait & $\begin{array}{l}26 . \\
08\end{array}$ & $\begin{array}{l}10 . \\
92 \\
\end{array}$ & $\begin{array}{l}20 . \\
44 \\
\end{array}$ & $\begin{array}{c}9.7 \\
4 \\
\end{array}$ & $\begin{array}{l}23 . \\
18 \\
\end{array}$ & $\begin{array}{c}11.5 \\
2 \\
\end{array}$ & $\begin{array}{c}21.1 \\
1 \\
\end{array}$ & $\begin{array}{c}11.5 \\
5 \\
\end{array}$ & .81 & .002 & $9.59^{* *}$ & .022 & 2.07 & .005 \\
\hline & & & & & & $<.0$ & $p<$. & $* * p<$ & & & & & & \\
\hline
\end{tabular}


Sbrana, Serena, \& De Miguel, A. (2020) Relevance Of Temperament Traits In Sexual Fluidity In A Sample Of Spanish Young University Students. Advances in Social Sciences Research Journal, 7(5) 369-381.

Table 3. Correlations among temperament factors

\begin{tabular}{|c|c|c|c|c|c|c|c|c|}
\hline & BFI-E & BFI-A & BFI-C & BFI-N & BFI-O & SSS-DESI & SSS-SAB & STAI-T \\
\hline BFI-A & $.17^{* * *}$ & & & & & & & \\
\hline BFI-C & .05 & -.03 & & & & & & \\
\hline BFI-N & $-.19^{* * *}$ & $-.18^{* * *}$ & .09 & & & & & \\
\hline BFI-O & $.11^{*}$ & .01 & $.15^{* *}$ & -.04 & & & & \\
\hline SSS-DESI & $.26^{* * *}$ & .04 & $-.22^{* * *}$ & $.11^{*}$ & .02 & & & \\
\hline SSS-SAB & .09 & $-.15^{* *}$ & -.02 & .01 & $.12^{*}$ & $.34^{* * *}$ & & \\
\hline STAI-T & $-.17^{* * *}$ & $-.13^{* *}$ & $-.15^{* * *}$ & $.53^{* * *}$ & .01 & $.11^{*}$ & $.22^{* *}$ & \\
\hline STAI-S & $-.13^{* *}$ & $-.11^{*}$ & $-.14^{* *}$ & $.46^{* * *}$ & -.05 & $.10^{*}$ & $.24^{* * *}$ & $.79^{* * *}$ \\
\hline \multicolumn{9}{|c|}{${ }^{*} p<.05 ;{ }^{* *} p<.01 ;{ }^{* * *} p<.001$} \\
\hline
\end{tabular}

Table 4. Summary of Multiple Regression Analysis for Variables Predicting sexual fluidity

\begin{tabular}{|c|c|c|c|c|c|c|c|c|c|}
\hline & \multicolumn{3}{|c|}{ Total sample } & \multicolumn{3}{|c|}{ Women } & \multicolumn{3}{|c|}{ Men } \\
\hline & $B$ & $\beta$ & $t$ & $B$ & $\beta$ & $t$ & $B$ & $\beta$ & $t$ \\
\hline Gender ${ }^{\mathrm{a}}$ & -7.03 & $\begin{array}{c}- \\
.32\end{array}$ & $-7.78^{* * *}$ & --- & --- & --- & --- & --- & --- \\
\hline Sexual orientation ${ }^{b}$ & -3.90 & $\begin{array}{c}- \\
.22\end{array}$ & $-5.38^{* * *}$ & -5.06 & $\begin{array}{c}- \\
.26\end{array}$ & $-5.25^{* * *}$ & $\begin{array}{c}- \\
2.85\end{array}$ &. & $-2.62^{* *}$ \\
\hline \multicolumn{10}{|c|}{ BFI } \\
\hline Extroversion & -.00 & & -.06 & .01 & & .13 & .01 & & .17 \\
\hline Agreeableness & -.06 & & -1.32 & -.09 & & -1.72 & .02 & & .21 \\
\hline Conscientiousness & -.05 & & -1.23 & -.04 & & -.81 & -.07 & & -.78 \\
\hline Neuroticism & -.07 & & -1.4 & -.08 & & -1.27 & -.13 & & -1.27 \\
\hline $\begin{array}{l}\text { Openness to } \\
\text { experience }\end{array}$ & 2.11 & .20 & $4.77^{* * *}$ & 1.69 & .16 & $3.24 * * *$ & 3.17 & .31 & $3.82^{* * *}$ \\
\hline SSS & & & & & & & .05 & & .52 \\
\hline Disinhibition & .95 & .23 & $5.51^{* * *}$ & .92 & .24 & $4.80^{* * *}$ & 1.02 & .22 & $2.67^{* *}$ \\
\hline $\begin{array}{c}\text { Boredom } \\
\text { Susceptibility }\end{array}$ & .07 & & 1.59 & .08 & & 1.37 & & & \\
\hline \multicolumn{10}{|c|}{ STAI } \\
\hline Trait Anxiety & .17 & .19 & $4.55^{* * *}$ & .20 & .23 & $4.48^{* * *}$ & -.10 & & -.70 \\
\hline State Anxiety & .02 & & .36 & -.07 & & -.84 & .17 & .20 & $2.47^{* *}$ \\
\hline$R^{2}$ & \multicolumn{3}{|c|}{.28} & \multicolumn{3}{|c|}{.24} & \multicolumn{3}{|c|}{.18} \\
\hline NOTE: & vom & & 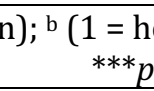 & $\begin{array}{l}\text { osexu } \\
.001\end{array}$ & & al; 3 & ros & & \\
\hline
\end{tabular}




\section{FIGURES}

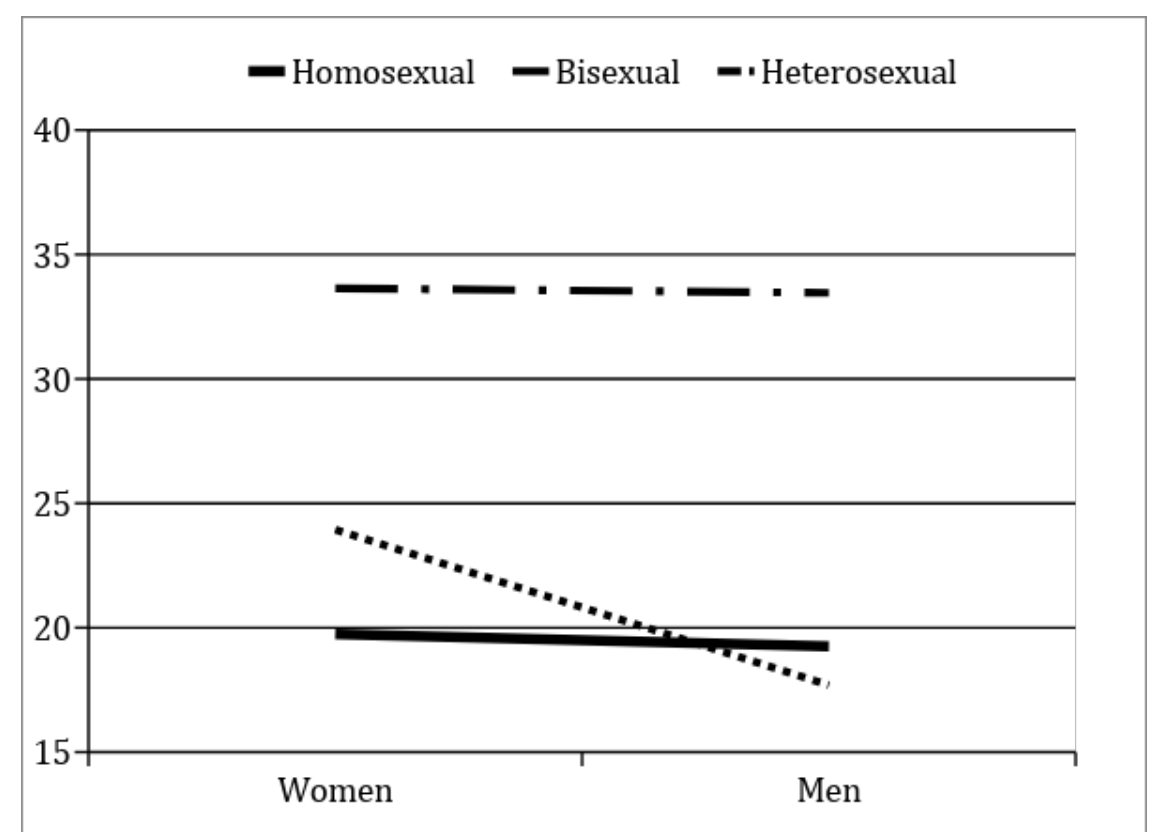

Figure 1: Mean score of sexual fluidity gender and sexual orientation

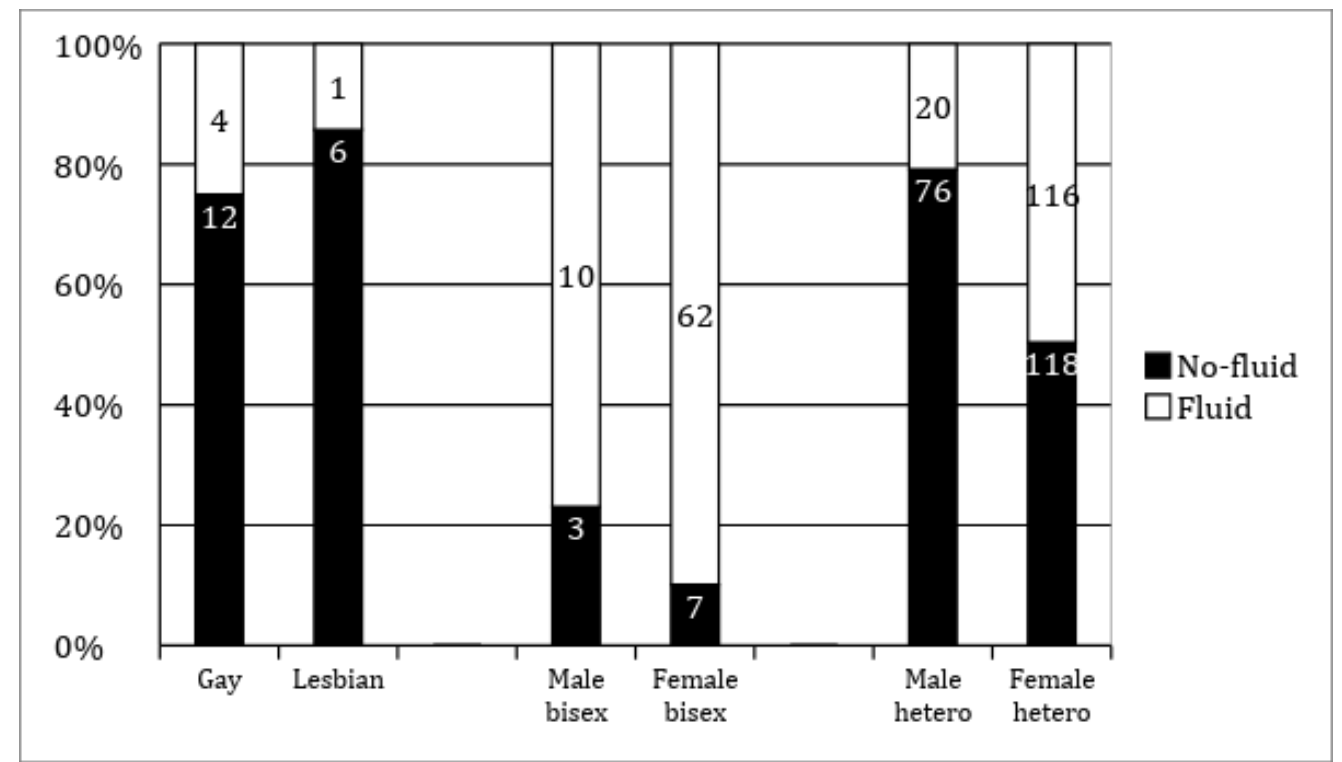

Figure 2: Sample distribution for sexual fluidity based on sexual orientation 